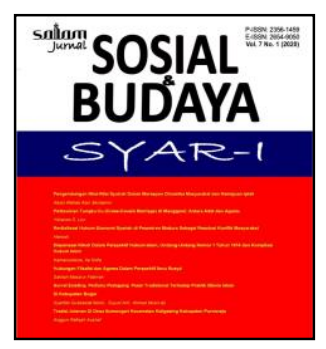

\author{
Jurnal Sosial dan Budaya Syar-i \\ P-ISSN: 2356-1459. E-ISSN: 2654-9050 \\ Vol. 8 No. 2 (2021), pp. $585-600$ \\ DOI: 10.15408/sjsbs.v8i2.20503 \\ http://journal.uinjkt.ac.id/index.php/salam/index
}

\title{
Pengaruh Bimbingan Konseling dan Pembelajaran Akidah Akhlak Terhadap Perilaku Keberagamaan Siswa Di Mts Ma'had Al-Zaytun Indramayu*
}

\author{
Iis Humaeroh ${ }^{1}$ \\ Program Studi Pendidikan Agama Islam \\ Pascasarjana IAIN Syekh Nurjati Cirebon \\ 10.15408/sjsbs.v8i2.20503
}

\begin{abstract}
Class IX will soon graduate and continue to higher education. For this reason, scientific provisions in learning morals and counseling are needed to prepare graduates who are smart and have good morals. This study was to determine the effect of counseling guidance and learning akidah akhlak on students' religious behavior in MTs. Ma'had Al-Zaytun Indramayu. The object of this research is the students of class IX MTs Ma'had Al-Zaytun Indramayu. This research was conducted on 135 respondents using a quantitative descriptive approach. Methods of data collection using survey methods, with the research instrument is a questionnaire. The approach used in this research is SPSS. This study proves that counseling guidance has a positive and significant effect on students 'religious behavior, which means that counseling plays a role in improving students' religious behavior. Learning akidah akhlak also has a positive and significant effect on students 'religious behavior, which can be interpreted that learning akidah akhlak plays a role in improving students' religious behavior. So, counseling and learning of akidah akhlak together have a positive and significant effect on students' religious behavior.
\end{abstract}

Keywords: Counseling Guidance, Learning Akidah Akhlak, Students' Religious Behavior

\begin{abstract}
Abstrak
Kelas IX akan segera lulus dan melanjutkan ke jenjang pendidikan yang lebih tinggi. Untuk itu bekal keilmuan dalam pembelajaran akidah akhlak dan bimbingan konseling sangat diperlukan untuk menyiapkan lulusan yang cerdas dan berakhlakul karimah. Penelitian ini untuk mengetahui pengaruh bimbingan konseling dan pembelajaran akidah akhlak terhadap perilaku keberagamaan siswa di MTs. Ma'had Al-Zaytun Indramayu. Objek penelitian ini adalah siswa kelas IX MTs. Ma'had Al-Zaytun Indramayu. Penelitian ini dilakukan terhadap 135 responden dengan menggunakan pendekatan deskriptif kuantitatif. Metode pengumpulan data menggunakan metode survey, dengan instrument penelitian adalah kuesioner. Pendekatan yang digunakan dalam penelitian ini adalah SPSS. Penelitian ini membuktikan bahwa bimbingan konseling berpengaruh positif dan signifikan terhadap perilaku keberagamaan siswa, yang mana dapat diartikan bahwa bimbingan konseling berperan dalam meningkatkan perilaku keberagamaan siswa. Pembelajaran akidah akhlak juga berpengaruh positif dan signifikan terhadap perilaku keberagamaan siswa, yang mana dapat diartikan bahwa Pembelajaran akidah akhlak berperan dalam meningkatkan perilaku
\end{abstract}

* Received: March 25, 2021, Revision: April 25, 2021, Published: April 28, 2021.

${ }^{1}$ Iis Humaeroh adalah mahasiswi Program Studi Pendidikan Agama Islam, Pascasarjana IAIN Syekh Nurjati Cirebon. Email:iishumaeroh770@gmail.com 
keberagamaan siswa. Jadi, bimbingan konseling dan pembelajaran akidah akhlak secara bersama-sama berpengaruh positif dan signifikan terhadap perilaku keberagamaan siswa.

Kata Kunci: Bimbingan Konseling, Pembelajaran Akidah Akhlak, Perilaku Keberagamaan Siswa

\section{A. PENDAHULUAN}

Pada proses pembelajaran di sekolah, output yang diharapkan tidak hanya sekedar nilai atau prestasi siswa. Namun lebih dari itu yakni kepribadian siswa yang ditandai dengan perilaku kepribadiannya. Kepribadian seseorang bukan ditentukan dari seberapa banyak kekayaan materi maupun tingginya ilmu pengetahuan yang diraihnya, akan tetapi yang lebih diutamakan ialah etika atau moralnya. Etika dan moral menggambarkan bagaimana karakter perilaku seseorang dalam menjalani kehidupan bermasyarakat. Perilaku-perilaku yang muncul bisa dalam bentuk perilaku yang positif maupun perilaku yang negatif, tergantung seberapa paham seseorang terhadap aturan, nilai-nilai maupun norma-norma yang ada.

Perilaku secara pengertian adalah tingkah laku manusia dan berbentuk dari jiwa, dan yang tertera di kamus besar bahasa Indonesia bahwa perilaku adalah tanggapan atau reaksi individu terhadap rangsangan atau lingkungan. ${ }^{2}$ Perilaku yang baik, sopan santun, cara bicara dan bertatakrama merupakan sikap yang selalu dipuja dan dipuji oleh setiap orang, kesopanan ini juga merupakan cermin bagi diri. Berdasarkan konsep tersebut, jalur pendidikan yang diselenggarakan di jenjang sekolah melalui kegiatan belajar mengajar secara berkesinambungan, tidaklah dititikberatkan atas satu pihak, akan tetapi rasa kebersamaan yang mendasarinya. ${ }^{3}$

Pembelajaran Aqidah Akhlak diajarkan tentang berperilaku baik yang sesuai dengan ajaran agama islam seperti: diajarkan norma, moral, etika dan cara tata krama yang baik, cara bergaul, cara menghargai orang dan sebagainya. ${ }^{4}$ MTs. Ma'had AlZaytun adalah lembaga pendidikan yang mengedepankan dua sistem pendidikan yang terpadu, dengan tujuan menciptakan generasi Islam yang balance (seimbang), yaitu menugasi duniawi dan menugasi ilmu akhirat, sistem pendidikan ini dibagi secara $50 \%$ : $50 \%$ dalam merancang dunia pendidikannya, dan pendidikan Akidah Akhlak di lembaga pendidikan ini telah dilaksanakan. Akan tetapi pengamatan penulis selama menjadi guru di sekolah tersebut, masih terdapat beberapa siswa yang belum paham tentang agama Islam, seperti: (1) Masih ada sebagian siswa dalam bergaul mengucapkan kata-kata yang tidak sopan, (2) Masih ada sebagian siswa yang suka mengejek temannya, (3) Masih ada diantara siswa yang membeda-bedakan teman dalam bergaul, (4) Masih ada diantara siswa yang tidak mengikuti kegiatan keagamaan di sekolah, dan (5) Masih ada diantara siswa kurang lancar membaca dan tidak tahu hukum tajwid dalam bacaan.

2 Anonimous, Pedoman Pendidikan Agama Islam, (Jakarta: Depag RI 1996). hlm. 755

${ }_{3}^{3}$ Anonimous, Pedoman Pendidikan Agama Islam, (Jakarta: Depag RI 1996). hlm. 4

${ }^{4}$ Siska Fitri Yanti. Pengaruh Pembelajaran Aqidah Akhlak Terhadap Perilaku Siswa di Madrasah Aliyah Negeri Kampar Timur. JOM FISIP Vol. 4 No. 1 - Februari 2017 
Resky Pratiwi dalam penelitiannya menunjukkan hasil bahwa terdapat pengaruh yang signifikan antara pembelajaran Aqidah akhlak terhadap perilaku peserta didik kelas V di MIN 2 Makassar. Hal ini tercermin dalam output SPSS Berdasarkan tabel Anova dapat kita ketahui bawa sig.deviation from linierity sebesar 0,235 dalam hal ini nilai 0,235 > 0,05 yang merupakan standar signifikansi maka dapat kita simpulkan bahwa diterima yang artinya terdapat hubungan linier atara variabel pembelajaran aqidah dengan perilaku peserta didik. ${ }^{5}$

Bimbingan dan konseling adalah salah satu bentuk pelayanan bantuan untuk peserta didik, baik secara perorangan maupun kelompok agar mandiri dan bisa berkembang secara optimal, dalam bimbingan pribadi, sosial, belajar maupun karier melalui berbagai jenis layanan dan kegiatan pendukung berdasarkan norma-norma yang berlaku (SK Mendikbud No.025/D/1995). Bimbingan dan konseling merupakan upaya proaktif dan sistematik dalam memfasilitasi individu mencapai tingkat perkembangan yang optimal, pengembangan perilaku yang efektif, pengembangan lingkungan, dan peningkatan fungsi atau manfaat individu dalam lingkungannya. ${ }^{6}$

Kesulitan siswa dalam menyesuaikan diri sering dijumpai di sekolah yang ditampilkan dalam bentuk perilaku, seperti rendah hati, agresivitas, mencari rasa aman pada berbagai bentuk mekanisme pertahanan diri (seperti rasionalisasi, proyeksi, egosentris dan sebagainnya), melanggar tata tertib, menetang guru, berkelahi, tidak melaksanakan tugas sekolah, mengisolasi diri dan sulit bekerja sama dalam situasi kelompok, seringkali permasalahan yang biasa dan dianggap wajar terjadi disekolahsekolah. Untuk mengatasi perilaku siswa, setiap sekolah mempunyai guru bimbingan konseling atau yang biasa disebut guru BK. Dilingkungan sekolah, siswa dituntut mampu berkomunikasi dengan baik dengan warga sekolah yakni guru, staf tata usaha dan teman sebaya, maupun personil sekolah lainnya. ${ }^{7}$ Takapaha dalam penelitiannya menunjukkan hasil bahwa terdapat pengaruh yang positif dan signifikan antara pemberian bimbingan konseling terhadap perilaku siswa. ${ }^{8}$

MTs. Ma'had Al-Zaytun Indramayu merupakan salah satu lembaga pendidikan yang sederajat dengan Sekolah Menengah Pertama, dengan lebih mengutamakan tentang pembelajaran agama Islam. Hal ini bertujuan agar siswa dapat meningkatkan keyakinan, pemahaman, penghayatan, dan pengalaman terhadap keyakinan dan keimanan yang benar dan menekankan pada pembiasaan untuk melaksanakan akhlah terpuji (prilaku yang baik) dan menjauhi akhlak tercela (prilaku buruk). Berdasarkan pengamatan dan wawancara yang telah dilakukan peneliti, menunjukkan bahwa banyak menemui siswa-siswi yang belum bisa bertutur kata sopan terhadap bapak/ibu

${ }^{5}$ Resky Pratiwi. 2018. Pengaruh Pembelajaran Aqidah Akhlak Terhadap Perilaku Peserta Didik Kelas V di MIN 2 Makassar. Skripsi UIN Alauddin Makassar

${ }^{6}$ Lutfi Diniyah. Pengaruh Bimbingan Konseling Terhadap Perubahan Tingkah Laku Siswa Kelas IX DI SMP NEGERI 2 Kandat Kabupaten Kediri Tahun Pelajaran 2014/2015. Skripsi Universitas Nusantara PGRI Kediri. 2016

${ }^{7}$ David Yohanis Takapaha, dkk. 2016. Pengaruh Komunikasi Antar Persona Guru Bimbingan Konseling Terhadap Perilaku Siswa (Studi Pada Siswa SMK Negeri 2 Kendari)

${ }^{8}$ David Yohanis Takapaha, dkk. 2016. Pengaruh Komunikasi Antar Persona Guru Bimbingan Konseling Terhadap Perilaku Siswa (Studi Pada Siswa SMK Negeri 2 Kendari) 
guru sebagai contoh "selamat pagi bro", tidak menghormati dengan guru sebagai contoh "tidak membungkukkan badan ketika lewat didepannya", berbicara dengan suara yang keras kepada guru, tidak mendengarkan perkataan guru sebagai contoh "ketika dinasehati malah berbicara sendiri dengan temannya".

Berdasarkan pemaparan di atas, maka dalam hal ini penulis ingin melakukan penelitian dengan judul "Pengaruh bimbingan konseling dan pembelajaran akidah akhlak terhadap perilaku keberagamaan siswa di MTs. Ma'had Al-Zaytun Indramayu."

\section{B. METODE PENELITIAN}

Jenis penelitian yang digunakan dalam penelitian ini adalah kuantitatif. Metode kuantitatif digunakan untuk meneliti populasi tertentu dengan analisis data statistik dengan tujuan pengujian hipotesis yang telah ditetapkan. Penelitian ini termasuk dalam tipe penelitian korelasional. Penelitian korelasional merupakan penelitian yang meneliti hubungan atau pengaruh antara dua variabel atau lebih. Penelitian ini termasuk korelasional karena sesuai dengan tujuan penelitian yang ingin meneliti adanya pengaruh pembelajaran bimbingan konseling dan pembelajaran akidah akhlak terhadap perilaku siswa.

Populasi pada penelitian ini adalah siswa kelas IX MTs. Ma'had Al-Zaytun Indramayu sebanyak 450 siswa. Dalam penelitian ini menggunakan sampel teori Arikunto 9 , yaitu $30 \%$ dari jumlah populasi. Maka sampel dalam penelitian ini adalah $30 \% \times 450=135$ siswa yang diambil secara acak dari setiap kelas, sehingga didapatkan 4-5 siswa per kelas. Teknik pengumpulan data menggunakan instrumen atau alat yang disebut dengan angket. Angket menggunakan skala likert yang berhubungan pendapat dan penilaian responden. Angket disusun dengan metode tertutup dan dibagikan pada responden. Pernyataan pada angket disusun melalui proses adopsi.

Adapun analisis data yang digunakan dalam penelitian ini menggunakan software SPSS 20 yang meliputi uji validitas, uji reliabilitas, uji asumsi klasik, uji regresi linier berganda, dan uji hipotesis.

\section{HASIL TEMUAN DAN PEMBAHASAN}

\section{Bimbingan Konseling}

Bimbingan konseling merupakan proses bantuan atau pertolongan yang diberikan oleh konselor kepada konseli melalui pertemuan tatap muka atau hubungan timbal balik antara keduanya, agar konseli memiliki kemampuan atau kecakapan melihat dan menemukan masalahnya serta mampu memecahkan masalahnya sendiri. ${ }^{10}$ Untuk itu, bimbingan dan konseling diartikan sebagai upaya yang diberikan kepada seseorang atau individu yang bersangkutan supaya dapat mencapai taraf

\footnotetext{
${ }_{9}^{9}$ Arikunto Suharsimi, Manajemen Penelitian. (Jakarta : Rineka Cipta, 2005)

${ }^{10}$ Devie Widyasari. 2012. Pengaruh Bimbingan Konseling Dan Kedisiplinan Belajar Siswa Terhadap Prestasi Belajar Siswa Kelas XI Pada SMA Negeri I Jatisrono Wonogiri Tahun Ajaran 2011/2012
} 
perkembangan dan kebahagiaan yang optimal dalam menjalani proses pemahaman, penerimaan, dan penyesuaian di lingkungan sekitar. ${ }^{11}$

\section{Pembelajaran Akidah Akhlak}

Secara umum pembelajaran Aqidah Akhlak di Madrasah Tsanawiyah mengarah kepada pemahaman dan penghayatan isi yang terkandung dalam Akidah Akhlak yang diharapkan dapat diwujudkan dalam kehidupan sehari-hari. Mata pelajaran Akidah Akhlak adalah salah satu mata pelajaran dalam rumpun Pendidikan Agama Islam yang mengandung makna sebagai pengetahuan, pemahaman dan penghayatan ajaran Islam sebagai pedoman hidup. Dengan demikian karakteristik mata pelajaran Aqidah Akhlak menekankan pada pengetahuan, pemahaman dan penghayatan terhadap pedoman hidup yang dapat dijadikan pola perilaku dalam kehidupan sehari-hari. Olehnya itu, dalam pembelajaran aqidah akhlak tidak hanya mengarah pada persoalan teoritis dalam aspek kognitif, tapi bermuara pula pada aspek afektif dan psikomotorik. Dalam pembelajaran Aqidah Akhlak terdapat tujuan yang hakiki yakni menanamkan dan meningkatkan keimanan serta mempertinggi kesadaran untuk berakhlak mulia sehingga peserta didik menjadi manusia yang beriman dan bertakwa kepada Allah SWT. ${ }^{12}$

\section{Perilaku Keberagaman Siswa}

Perilaku keberagamaan adalah perilaku, sikap dan pengalaman keberagamaan yang dipraktekkan oleh siswa dalam kehidupan keseharian mereka. Perilaku keberagamaan siswa di sekolah dipengaruhi oleh beberapa hal. Pertama, pengaruh internal yaitu seperangkat sistem yang diterapkan oleh sekolah berupa kurikulum pelajaran agama, materi pelajaran agama, buku paket pelajaran agama yang dimaksudkan untuk mempengaruhi pola keberagamaan siswa. Kedua, pengaruh eksternal yaitu lebih bersifat environmental. Artinya, situasi lingkungan sosial tempat anak-anak sekolah hidup dan bergaul secara sosial turut serta mempengaruhi pola keberagamaan seorang siswa. ${ }^{13}$

\section{Paradigma Penelitian}

Berdasarkan landasan teori yang ada secara garis besar paradigma penelitian ini dapat digambarkan sebagai berikut :

\footnotetext{
${ }^{11}$ Lok cit, Ahmad Susanto, hal 1

${ }^{12}$ Sufiani, Efektivitas Pembelajaran Aqidah Akhlak Berbasis Manajemen Kelas, Jurnal AlTa'dibVol. 10 No. 2, Juli-Desember, 2017

${ }^{13}$ Kadir. 2008. Pola Perilaku Keberagamaan Siswa SMA Negeri Kabupaten Mais Ok War I. Jurnal "Al-Qalam" No. Xxii Tahun Xiv Edisi Juli - Desember 2008
} 


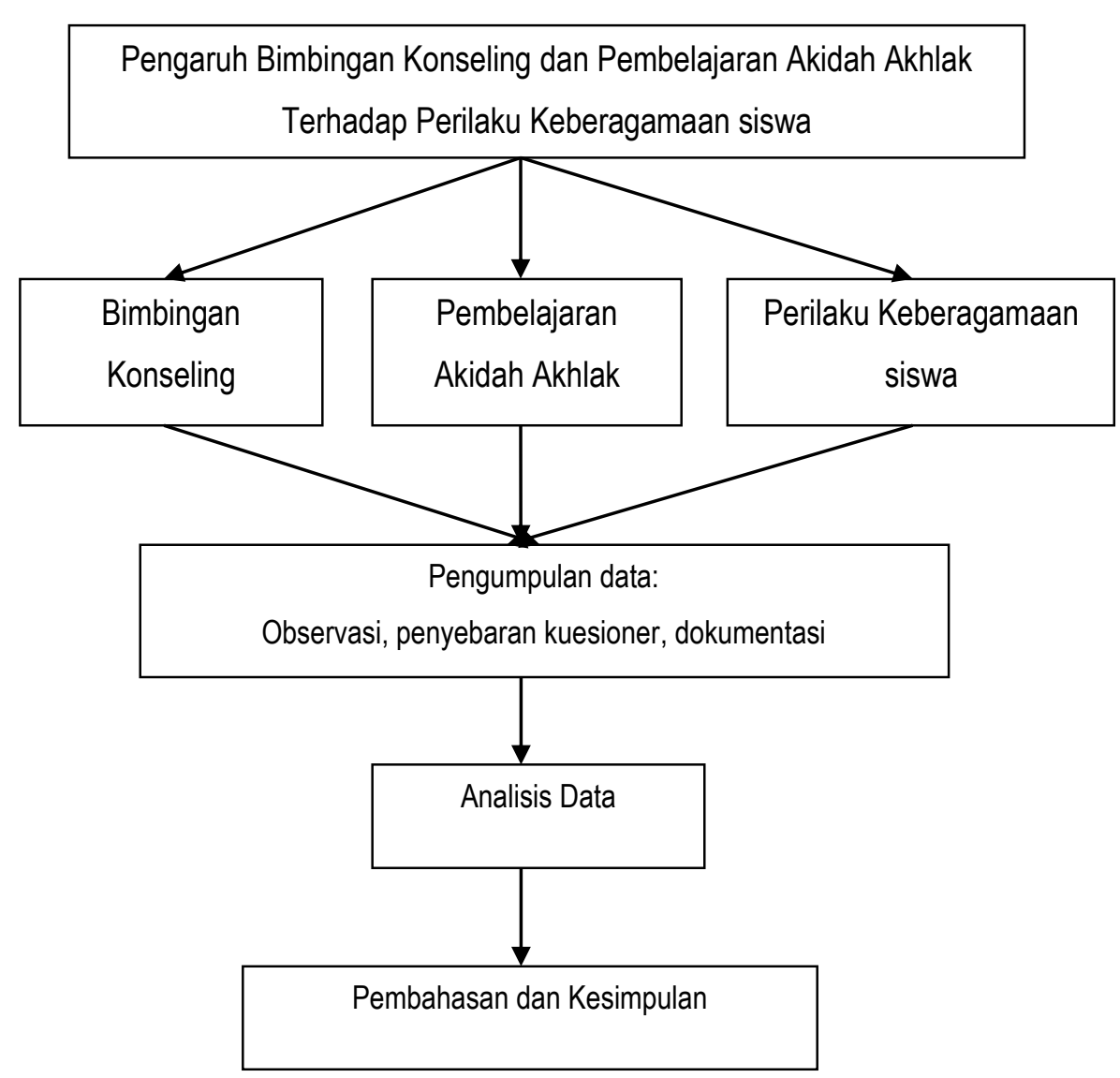

Gambar 1. Paradigma Penelitian

Dengan demikian dalam penelitian ini, penulis membuat sebuah hipotesis sebagai berikut :

H1 : Bimbingan Konseling berpengaruh positif terhadap Perilaku keberagaman siswa.

H2 : Pembelajaran akidah akhlak berpengaruh positif terhadap Perilaku keberagaman siswa.

H3 : Bimbingan Konseling dan pembelajaran akidah akhlak berpengaruh positif terhadap Perilaku keberagaman siswa.

\section{Sejarah Singkat dan Perkembangannya}

Madrasah Tsanawiyah (MTs) Ma'had Al-Zaytun berada dalam Yayasan Pesantren Indonesia (YPI). MTs Ma'had Al-Zaytun merupakan madrasah yang pertama kali diselenggarakan di Ma'had Al-Zaytun. Awal pembelajaran dibuka pada tanggal 1 Juli 1999, dan peresmian pembukaannya secara umum dilakukan pada 27 Agustus 1999 oleh Presiden RI Ketiga, Prof.Dr.Ing. B.J. Habibie. Pada awalnya gedung Abu Bakar sebagai ruang pembelajaran. Sekarang ruang-ruang kelas pembelajaran MTs Ma'had AlZaytun di gedung Ali bin Abi Thalib. Gedung Ali bin Abi Thalib terdiri dari 5 lantai dan 
basement seluas $18.700 \mathrm{~m}^{2}$, diperuntukkan untuk kelas dan perkantoran MTs. Siswasiswi MTs Ma'had Al-Zaytun berasal dari provinsi-provinsi di Indonesia dan beberapa negara tetangga seperti Singapura dan Malaysia.

Pada tanggal 4 Februari 2002, Kanwil Departemen Agama Provinsi Jawa Barat mengeluarkan Surat Keputusan No. Wi/I/PP.03.2/476/2002 tentang pemberian status dan akreditasi kepada Madrasah Tsanawiyah Al-Zaytun. Status yang pertama diberikan adalah "Diakui". Seiring perubahan peraturan tentang pemberian status sekolah/madrasah, maka Al-Zaytun diajukan untuk dilakukan penilaian oleh Dewan Akreditasi Madrasah (DAM). Pada tanggal 18 Januari 2006, MTs Al-Zaytun ditetapkan sebagai sebagai Madrasah Terakreditasi Peringkat A (sangat baik/unggul) dengan piagam No. A/Kw.10.4/MTs./14/057/2006.

Masa berlaku piagam tersebut di atas adalah 4 tahun, maka setelah itu dilakukan akreditasi ulang. Badan akreditasi yang menilai berbeda dengan yang sebelumnya. Akreditasi ulang dilakukan oleh Badan Akreditasi Nasional Sekolah/Madrasah di bawah naungan Departemen Pendidikan Nasional. Akreditasi yang diperoleh MTs AlZaytun adalah A (Amat Baik) dengan piagam bernomor 02.00/422/BAP-SM/X/2009 tertanggal 9 November 2010.

\section{Visi, Misi dan Tujuan MTs Ma'had Al-Zaytun}

Visi MTs Ma'had Al-Zaytun yaitu “Al-Zaytun pusat pendidikan pengembangan budaya toleransi dan perdamaian." Adapun Misi dan Tujuan MTs Ma'had Al-Zaytun yaitu "Mempersiapkan peserta didik beraqidah kokoh kuat terhadap Allah dan syari' atNya, menyatu dalam tauhid berakhlaqul karimah, berilmu pengetahuan luas, berketerampilan tinggi yang tersimpul dalam "Basthotan fi ilmi wal jismi" sehingga sanggup siap dan mampu hidup secara dinamis di lingkungan bangsanya dan masyarakat antar bangsa dengan penuh kesejahteraan dan kebahagiaan duniawi ukhrowi."

\section{Prestasi Sekolah}

Pada tahun 2017 MTs Ma'had Al-Zaytun menjadi juara umum AKSIOMA dan KSM tingkat kabupaten Indramayu. Kompetisi Sains Madrasah (KSM) tahun 2017 secara umum bertujuan untuk peningkatan mutu pendidikan sains di madrasah/sekolah secara komprehensif melalui penumbuhkembangan budaya belajar, kreatifitas dan motivasi dalam meraih prestasi terbaik dalam ridha Allah SWT dengan kompetisi yang sehat, menjunjung tinggi nilai-nilai Islam dan sportivitas dalam mempelajari dan memahami sains.

Ajang Kompetisi Seni dan Olah Raga Madrasah (AKSIOMA) adalah suatu kegiatan yang bersifat kompetisi di bidang seni dan olah raga antara siswa madrasah dalam lingkup wilayah atau tingkat lomba tertentu. Sasaran kegiatan ini adalah siswa madrasah Ibtidaiyah, Tsanawiyah dan Aliyah terbaik dalam bidang seni dan olahraga di masing-masing provinsi di Indonesia. 
Pada tahun 2016 - 2019 Madrasah Tsanawiyah (MTs) Ma'had Al-Zaytun kembali berpartisipasi di kedua ajang tersebut. Beberapa piala kategori lomba berhasil dibawa pulang ke Ma'had Al-Zaytun. Beberapa kejuaraan yang berhasil diraih oleh kontingan KSM dan AKSIOMA MTs Ma'had Al-Zaytun dalam 3 tahun terakhir yang terkait dengan penelitian ini, yakni pembelajaran berbasis komputer dan pembelajaran konvensional serta mata pelajaran bahasa Arab, tercantum dalam tabel 1 di bawah ini:

Tabel 1

Rincian Juara Kontingen KSM dan AKSIOMA MTs Ma'had Al-Zaytun 3 Tahun Terakhir

\begin{tabular}{|c|l|c|c|c|c|}
\hline No & \multicolumn{1}{|c|}{ Nama Kegiatan } & $\begin{array}{c}\text { Individual/ } \\
\text { Kelompok }\end{array}$ & Tingkat & Tahun & Pencapaian \\
\hline 1 & KSM Matematika & Individual & Kab/Kota & 2016 & Juara 1 \\
\hline 2 & KSM Fisika & Individual & Kab/Kota & 2016 & Juara 1 \\
\hline 3 & KSM Biologi & Individual & Kab/Kota & 2016 & Juara 2 \\
\hline 6 & $\begin{array}{l}\text { Aksioma Cabang Pidato Bahasa } \\
\text { Arab Putra }\end{array}$ & Individual & Provinsi & 2017 & Juara 3 \\
\hline 7 & KSM Matematika & Individual & Kab/Kota & 2017 & Juara 1 \\
\hline 8 & KSM Fisika & Individual & Kab/Kota & 2017 & Juara 1 \\
\hline 12 & $\begin{array}{l}\text { Aksioma Cabang Pidato Bahasa } \\
\text { Arab Putra }\end{array}$ & Individual & Kab/Kota & 2017 & Juara 1 \\
\hline 13 & Aksioma Cabang Kaligrafi & Individual & Kab/Kota & 2017 & Juara 1 \\
\hline 15 & $\begin{array}{l}\text { Aksioma Cabang Pidato Bahasa } \\
\text { Arab Putri }\end{array}$ & Individual & Kab/Kota & 2017 & Juara 2 \\
\hline 17 & KSM Biologi & Individual & Kab/Kota & 2017 & Juara 3 \\
\hline 19 & KSM Matematika & Individual & Kab/Kota & 2018 & Juara 1 \\
\hline 20 & KSM Matematika & Individual & Kab/Kota & 2018 & Juara 2 \\
\hline 21 & KSM IPS & Individual & Kab/Kota & 2018 & Juara 3 \\
\hline 23 & OSN IPA & Individual & Kab/Kota & 2019 & Juara 2 \\
\hline
\end{tabular}

\section{Tenaga Pendidik dan kependidikan}

Pada tahun 2019-2020, guru-guru yang mengajar di Madrasah Tsanawiyah (MTs) Ma'had Al-Zaytun berjumlah 106 orang yang berasal dari berbagai perguruan tinggi terkemuka di Indonesia dan pondok-pondok pesantren dengan kualifikasi dimulai dari S1 sampai dengan S2. Sebagaimana tercantum dalam tabel 4.2 di bawah ini:

Tabel 2

Jumlah Pendidik MTs Ma'had Al-Zaytun Berdasarkan Kualifikasi

\begin{tabular}{|l|c|c|}
\hline \multicolumn{1}{|c|}{ Kualifikasi } & Jumlah & Persentase \\
\hline Magister (S2) & 6 orang & $6 \%$ \\
\hline
\end{tabular}




\begin{tabular}{|l|c|c|}
\hline Sarjana (S1) & 99 orang & $93 \%$ \\
\hline Sarjana Muda (D3) & 1 orang & $1 \%$ \\
\hline Diploma II (D2) & - & - \\
\hline Diploma (D1) & - & - \\
\hline Total & 106 orang & $100 \%$ \\
\hline
\end{tabular}

\section{Keadaan Siswa}

Pada tahun 2019-2020, siswa MTs Ma'had Al-Zaytun berjumlah 1985 orang. Adapun siswa kelas IX MTs Ma'had Al-Zaytun kecamatan Gantar kabupaten Indramayu yang berjumlah 687 siswa yang terdiri dari 21 rombel. Rekapitulasi data siswa MTs Ma'had Al-Zaytun dalam 3 tahun terakhir sebagaimana tercantum dalam tabel 4.3 berikut ini:

Tabel 3

Rekapitulasi Data Siswa MTs Ma'had Al-Zaytun 3 Tahun Terakhir

\begin{tabular}{|l|l|l|l|l|l|l|l|l|}
\hline \multirow{2}{*}{$\begin{array}{l}\text { Tahun } \\
\text { Ajaran }\end{array}$} & \multicolumn{2}{|c|}{ Kls } & $\mathbf{7}$ & \multicolumn{1}{c|}{ Kls } & \multicolumn{2}{c|}{ Kls } & \multicolumn{2}{c|}{ Total } \\
\cline { 2 - 8 } & $\begin{array}{l}\text { Jml } \\
\text { Siswa }\end{array}$ & $\begin{array}{l}\text { Jml } \\
\text { Rombel }\end{array}$ & $\begin{array}{l}\text { Jml } \\
\text { Siswa }\end{array}$ & $\begin{array}{l}\text { Jml } \\
\text { Rombel }\end{array}$ & $\begin{array}{l}\text { Jml } \\
\text { Siswa }\end{array}$ & $\begin{array}{l}\text { Jml } \\
\text { Rombel }\end{array}$ & $\begin{array}{l}\text { Jml } \\
\text { Siswa }\end{array}$ & $\begin{array}{l}\text { Jml } \\
\text { Rombel }\end{array}$ \\
\hline $\begin{array}{l}2016- \\
2017\end{array}$ & 719 & 20 & 587 & 17 & 452 & 13 & 1758 & 50 \\
\hline $\begin{array}{l}2017- \\
2018\end{array}$ & 743 & 22 & 703 & 20 & 562 & 17 & 2008 & 59 \\
\hline $\begin{array}{l}2018- \\
2019\end{array}$ & 584 & 19 & 715 & 21 & 649 & 19 & 1948 & 59 \\
\hline $\begin{array}{l}2019- \\
2020\end{array}$ & 722 & 21 & 576 & 18 & 687 & 21 & 1985 & 60 \\
\hline
\end{tabular}

\section{Sarana dan Prasarana}

Luas lahan kampus Al-Zaytun beserta pendukungnya, yang MTs Al-Zaytun merupakan bagian jenjang pendidikan yang diselenggarakan di kampus Ma'had AlZaytun adalah 1.200 Ha. Keseluruhannya merupakan tanah wakaf yang diberikan kepada Yayasan Pesantren Indonesia. Lahan seluas 200 Ha dipergunakan untuk arena pendidikan dan selebihnya untuk sarana pendukung berupa areal pertanian, perikanan, perkebunan, kehutanan dan lain-lain.

Sarana fisik untuk pelaksanaan pendidikan terdiri dari bangunan sekolah, asrama pelajar, sarana olahraga dan kesenian, bangunan peribadatan, fasilitas umum dan fasilitas pendukung. Ruang-ruang kelas pembelajaran MTs Ma'had Al-Zaytun yang berjumlah 60 ruang berada di gedung Ali bin Abi Thalib. Gedung Ali bin Abi Thalib terdiri dari 5 lantai dan basement seluas $18.700 \mathrm{~m}^{2}$, diperuntukkan untuk kelas dan perkantoran MTs. Adapun siswa-siswi MTs Ma'had Al-Zaytun berasal dari seluruh provinsi di Indonesia dan beberapa negara tetangga seperti Singapura dan Malaysia. 
Asrama pelajar yang sudah tersedia terdapat 5 unit, yaitu asrama Al-Fajar untuk santri putra Madrasah Aliyah, asrama Al-Nur untuk santri putri Madrasah Aliyah, asrama Al-Madani untuk santri putra Madrasah Tsanawiyah, asrama Al-Musthafa untuk santri putri Madrasah Tsanawiyah dan asrama Persahabatan untuk santri Madrasah Ibtidaiyah. Pelajar putra MTs Al-Zaytun yang menempati asrama Al-Madani yang terdiri dari 6 lantai seluas $28.850 \mathrm{~m}^{2}$ berjumlah 208 kamar, masing-masing kamar berukuran $84 \mathrm{~m}^{2}$. Sedangkan pelajar puteri MTs Al-Zaytun menempati asrama AlMusthafa yang terdiri dari 5 lantai seluas $22.000 \mathrm{~m}^{2}$ yang berjumlah 170 kamar, masingmasing kamar seluas $72 \mathrm{~m}^{2}$.

Sarana olahraga yang sudah dibangun adalah Gedung Serba Guna Al-Akbar, Stadion Palagan Agung dan Lapangan Medan Satria Wiratama. Gedung Al-Akbar terdiri dari 2 lantai seluas $10.800 \mathrm{~m}^{2}$. Lantai I diperuntukkan rumah makan pelajar dan lantai II gedung serba guna sekaligus untuk lapangan out door cabang olahraga basket, voli bola, bulu tangkis, tenis meja dan takraw. Stadion Palagan Agung memiliki tribune seluas $7000 \mathrm{~m}^{2}$. Dilengkapi fasilitas 2 unit dome untuk perkantoran Komite Olahraga dan Seni (KOSMAZ), ruang-ruang kesenian, penginapan atlit dan lapangan out door seluas $27.700 \mathrm{~m}^{2}$ yang terdiri dari 1 unit lapangan sepak bola, 2 lapangan hockey, 6 lapangan basket, 3 unit lapangan tenis, 6 unit lapangan voley dan track atletik. Lapangan Medan Satria Wiratama seluas $62.500 \mathrm{~m}^{2}$ memuat 6 lapangan sepak bola dan 1 unit lapangan hockey.

Bangunan peribadatan yang digunakan sampai saat ini adalah masjid Al-Hayat terdiri dari 2 lantai seluas $5000 \mathrm{~m}^{2}$. Masjid besar yang menjadi ikon Al-Zaytun adalah Masjid Rahmatan Lil 'Alamin seluas $77.000 \mathrm{~m}^{2}$ terdiri dari 6 lantai dan basement, dilengkapi dengan 1 unit menara seluas $9.500 \mathrm{~m}^{2}$ yang diberi nama Menara Pemuda dan Perdamaian. Tahapan pembangunan masjid tersebut sampai saat ini telah menyelesaikan seluruh struktur utama bangunan dan sedang proses pemasangan granit (dinding).

Fasilitas umum yang disiapkan Al-Zaytun antara lain: Wisma Tamu Al-Ishlah (penginapan/hotel) seluas $7.600 \mathrm{~m}^{2}$ terdiri dari 150 kamar, meeting room dan restaurant. Fasilitas umum lainnya rumah makan pelajar, kitchen, loundry, toserba, kantin umum, barbershop, garment, warpostel, penerimaan tamu (pendopo) dan beberapa fasilitas lainnya. Fasilitas pendukung kegiatan pendidikan antara lain laboratorium ilmu-ilmu dasar, laboratorium bahasa, laboratorium komputer, hitchery, empang-empang, lahanlahan pertanian (laboratorium alam), kandang-kandang ternak, kultur jaringan, ruang Inseminasi Buatan dan Embrio Transfer, Pengolahan susu, laboratorium beton, fabrikasi, meubeler, pabrik beras, pabrik gula, dapur, ruang redaksi Majalah Al-Zaytun, percetakan, power house dan lain-lain. Dalam kesehariannya seluruh siswa MTs tersebut diasramakan. Jadi setelah proses pembelajaran selesai dilaksanakan di gedung pembelajaran atau di kelas masing-masing, selanjutnya para siswa akan kembali ke asrama masing-masing untuk beristirahat atau mengikuti kegiatan lain yang telah diprogramkan. 


\section{Pengaruh Bimbingan Konseling $\left(X_{1}\right)$ terhadap Perilaku Keberagaman Siswa $(Y)$}

Metode yang digunakan untuk menguji hipotesis di atas adalah dengan menggunakan Uji t yakni untuk membuktikan "Ada pengaruh bimbingan konseling $\left(\mathrm{X}_{1}\right)$ secara parsial terhadap perilaku keberagaman siswa $(\mathrm{Y})$. Berikut hasil pengolahan data yang diperoleh pada perhitungan uji t:

Tabel 4.1 Pengujian Hipotesis dengan uji t

\section{Coefficients $^{\mathrm{a}}$}

\begin{tabular}{|rl|r|r|r|r|r|}
\hline \multicolumn{2}{|c|}{ Model } & \multicolumn{2}{|c|}{ Unstandardized Coefficients } & \multicolumn{1}{c|}{$\begin{array}{c}\text { Standardized } \\
\text { Coefficients }\end{array}$} & \multicolumn{1}{c|}{ Sig. } \\
\cline { 3 - 5 } & \multicolumn{1}{|c|}{ B } & \multicolumn{1}{c|}{ Std. Error } & \multicolumn{2}{c|}{ Beta } & & \\
\hline 1 & (Constant) & 1,266 &, 365 & & 3,467 &, 001 \\
& Rata_X1 &, 228 &, 089 &, 185 & 2,552 &, 012 \\
\hline
\end{tabular}

a. Dependent Variable: Rata_Y

Uji t dalam penelitian ini dilakukan dengan ketentuan sebagai berikut:

a. Jika signifikansi hasil $>0,05$ maka hipotesis ditolak.

b. Jika signifikansi hasil <0,05 maka hipotesis diterima.

Berdasarkan tabel 4.1 tersebut, dapat diketahui nilai t hitung untuk variabel bimbingan konseling $\left(X_{1}\right)$ sebesar 2,552 dengan nilai signifikan yang diperoleh sebesar 0,012. Hal tersebut menunjukkan bahwa variabel bimbingan konseling $\left(X_{1}\right)$ memiliki nilai signifikansi < 0,05; maka hipotesis diterima. Dengan demikian dapat dikatakan bahwa bimbingan konseling $\left(\mathrm{X}_{1}\right)$ berpengaruh positif dan signifikan secara parsial terhadap perilaku keberagaman siswa $(\mathrm{Y})$.

\section{Pengaruh Pembelajaran Akidah Akhlak $\left(X_{2}\right)$ terhadap Perilaku Keberagaman Siswa $(\mathrm{Y})$}

Metode yang digunakan untuk menguji hipotesis di atas adalah dengan menggunakan Uji t yakni untuk membuktikan "Ada pengaruh pembelajaran akidah akhlak $\left(\mathrm{X}_{2}\right)$ secara parsial terhadap perilaku keberagaman siswa $(\mathrm{Y})$. Berikut hasil pengolahan data yang diperoleh pada perhitungan uji t:

Tabel 4.2 Pengujian Hipotesis dengan uji $t$

\section{Coefficients ${ }^{a}$}

\begin{tabular}{|c|c|c|c|c|c|c|}
\hline \multirow{2}{*}{\multicolumn{2}{|c|}{ Model }} & \multicolumn{2}{|c|}{ Unstandardized Coefficients } & \multirow{2}{*}{$\begin{array}{c}\text { Standardized } \\
\text { Coefficients } \\
\text { Beta }\end{array}$} & \multirow[t]{2}{*}{$\mathrm{t}$} & \multirow[t]{2}{*}{ Sig. } \\
\hline & & $\mathrm{B}$ & Std. Error & & & \\
\hline & (Constant) & 1,266 &, 365 & & 3,467 & ,001 \\
\hline & Rata_X1 & ,401 &, 092 & ,316 & 4,353 &, 000 \\
\hline
\end{tabular}

a. Dependent Variable: Rata_Y 
Uji t dalam penelitian ini dilakukan dengan ketentuan sebagai berikut:

a. Jika signifikansi hasil >0,05 maka hipotesis ditolak.

b. Jika signifikansi hasil $<0,05$ maka hipotesis diterima.

Berdasarkan tabel 4.2 tersebut, dapat diketahui nilai t hitung untuk variabel pembelajaran akidah akhlak $\left(\mathrm{X}_{2}\right)$ sebesar 4,353 dengan nilai signifikan yang diperoleh sebesar 0,000. Hal tersebut menunjukkan bahwa variabel pembelajaran akidah akhlak $\left(\mathrm{X}_{2}\right)$ memiliki nilai signifikansi $<0,05$; maka hipotesis diterima. Dengan demikian dapat dikatakan bahwa pembelajaran akidah akhlak $\left(\mathrm{X}_{2}\right)$ berpengaruh positif dan signifikan secara parsial terhadap perilaku keberagaman siswa $(\mathrm{Y})$.

\section{Pengaruh Bimbingan Konseling $\left(X_{1}\right)$ dan Pembelajaran Akidah Akhlak $\left(X_{2}\right)$ terhadap Perilaku Keberagaman Siswa (Y)}

Metode yang digunakan untuk menguji hipotesis di atas adalah dengan menggunakan Uji F yakni untuk membuktikan "Ada pengaruh bimbingan konseling $\left(X_{1}\right)$ dan pembelajaran akidah akhlak $\left(X_{2}\right)$ secara bersama-sama terhadap perilaku keberagaman siswa (Y). Berikut hasil pengolahan data yang diperoleh pada perhitungan uji F:

Tabel 4.3 Pengujian Hipotesis dengan uji $\mathrm{F}$

ANOVA $^{\mathrm{a}}$

\begin{tabular}{|rl|r|r|r|r|r|}
\hline Model & & Sum of Squares & Df & Mean Square & F & Sig. \\
\hline \multirow{2}{*}{1} & Regression & 2,691 & 2 & 1,346 & 17,540 &, $000^{\circ}$ \\
& Residual & 13,272 & 173 &, 077 & & \\
& Total & 15,963 & 175 & & & \\
\hline
\end{tabular}

a. Dependent Variable: Rata_Y

b. Predictors: (Constant), Rata_X2, Rata_X1

Sumber: Hasil Pengolahan data menggunakan SPSS 20

Hasil pengujian diperoleh nilai $\mathrm{F}$ sebesar 17,540 dengan nilai signifikan yang diperoleh sebesar 0,000 di mana nilai tersebut lebih kecil dari 0,05. Dengan demikain dapat dijelaskan bahwa terdapat pengaruh positif dan signifikan secara bersama-sama antara variabel bimbingan konseling $\left(\mathrm{X}_{1}\right)$ dan pembelajaran akidah akhlak $\left(\mathrm{X}_{2}\right)$ terhadap variabel perilaku keberagaman siswa $(\mathrm{Y})$, sehingga hipotesis diterima. Hal ini dapat diartikan bahwa apabila bimbingan konseling $\left(\mathrm{X}_{1}\right)$ dan pembelajaran akidah akhlak $\left(\mathrm{X}_{2}\right)$ memiliki peningkatan nilai maka perilaku keberagaman siswa $(Y)$ juga akan meningkat.

\section{Pengaruh Bimbingan Konseling $\left(X_{1}\right)$ terhadap Perilaku Keberagaman Siswa $(Y)$}

Bimbingan konseling merupakan proses bantuan atau pertolongan yang diberikan oleh konselor kepada konseli melalui pertemuan tatap muka atau hubungan timbal balik antara keduanya, agar konseli memiliki kemampuan atau kecakapan 
melihat dan menemukan masalahnya serta mampu memecahkan masalahnya sendiri. ${ }^{14}$ Perilaku keberagaman adalah perilaku, sikap dan pengalaman keberagamaan yang dipraktekkan oleh siswa dalam kehidupan keseharian mereka. Perilaku keberagamaan siswa di sekolah dipengaruhi oleh beberapa hal. Pertama, pengaruh internal yaitu seperangkat sistem yang diterapkan oleh sekolah berupa kurikulum pelajaran agama, materi pelajaran agama, buku paket pelajaran agama yang dimaksudkan untuk mempengaruhi pola keberagamaan siswa. Kedua, pengaruh eksternal yaitu lebih bersifat environmental. Artinya, situasi lingkungan sosial tempat anak-anak sekolah hidup dan bergaul secara sosial turut serta mempengaruhi pola keberagamaan seorang siswa. ${ }^{15}$

Berdasarkan hasil penelitian yang telah dilakukan diketahui bahwa nilai t hitung untuk variabel bimbingan konseling $\left(X_{1}\right)$ sebesar 2,552 dengan nilai signifikan yang diperoleh sebesar 0,012. Hal tersebut menunjukkan bahwa variabel bimbingan konseling $\left(X_{1}\right)$ memiliki nilai signifikansi < 0,05; maka hipotesis diterima. Dengan demikian dapat dikatakan bahwa bimbingan konseling $\left(X_{1}\right)$ berpengaruh positif dan signifikan secara parsial terhadap perilaku keberagaman siswa $(\mathrm{Y})$.

Hasil ini sejalan dengan penelitian yang dilakukan oleh Takapaha berjudul "Pengaruh Komunikasi Antar Persona Guru Bimbingan Konseling Terhadap Perilaku Siswa (Studi Pada Siswa SMK Negeri 2 Kendari)" menunjukkan hasil bahwa terdapat pengaruh yang positif dan signifikan antara pemberian bimbingan konseling terhadap perilaku siswa. ${ }^{16}$ Bimbingan dan konseling merupakan upaya bantuan yang diberikan oleh guru pembimbing kepada siswa yang menggunakan prosedur, cara dan bahan agar individu mampu mandiri. Proses kemandirian individu tidak lepas dari adanya Komunikasi dalam proses sosialisasi di lingkungan dimana individu tersebut berada. Komunikasi sangat berperan dalam pembentukan kepribadian individu. Dengan komunikasi, individu dapat melangsungkan hidupnya baik di lingkungan keluarga, sekolah maupun di masyarakat. Dilingkungan sekolah, siswa dituntut mampu berkomunikasi dengan baik dengan warga sekolah yakni guru, staf tata usaha dan teman sebaya, maupun personil sekolah lainnya. ${ }^{17}$

\section{Pengaruh Pembelajaran Akidah Akhlak $\left(X_{2}\right)$ terhadap Perilaku Keberagaman Siswa (Y)}

Mata pelajaran Akidah Akhlak adalah salah satu mata pelajaran dalam rumpun Pendidikan Agama Islam yang mengandung makna sebagai pengetahuan, pemahaman

\footnotetext{
${ }^{14}$ Devie Widyasari. 2012. Pengaruh Bimbingan Konseling Dan Kedisiplinan Belajar Siswa Terhadap Prestasi Belajar Siswa Kelas XI Pada SMA Negeri I Jatisrono Wonogiri Tahun Ajaran 2011/2012

${ }^{15}$ Kadir. 2008. Pola Perilaku Keberagamaan Siswa SMA Negeri Kabupaten Mais Ok War I. Jurnal "Al-Qalam" No. Xxii Tahun Xiv Edisi Juli - Desember 2008

${ }^{16}$ David Yohanis Takapaha, dkk. 2016. Pengaruh Komunikasi Antar Persona Guru Bimbingan Konseling Terhadap Perilaku Siswa (Studi Pada Siswa SMK Negeri 2 Kendari)

${ }_{17}$ David Yohanis Takapaha, dkk. 2016. Pengaruh Komunikasi Antar Persona Guru Bimbingan Konseling Terhadap Perilaku Siswa (Studi Pada Siswa SMK Negeri 2 Kendari)
} 
dan penghayatan ajaran Islam sebagai pedoman hidup. Dalam pembelajaran Aqidah Akhlak terdapat tujuan yang hakiki yakni menanamkan dan meningkatkan keimanan serta mempertinggi kesadaran untuk berakhlak mulia sehingga peserta didik menjadi manusia yang beriman dan bertakwa kepada Allah SWT. ${ }^{18}$ Perilaku keberagaman adalah perilaku, sikap dan pengalaman keberagamaan yang dipraktekkan oleh siswa dalam kehidupan keseharian mereka. Perilaku keberagamaan siswa di sekolah dipengaruhi oleh beberapa hal. Pertama, pengaruh internal yaitu seperangkat sistem yang diterapkan oleh sekolah berupa kurikulum pelajaran agama, materi pelajaran agama, buku paket pelajaran agama yang dimaksudkan untuk mempengaruhi pola keberagamaan siswa. Kedua, pengaruh eksternal yaitu lebih bersifat environmental. Artinya, situasi lingkungan sosial tempat anak-anak sekolah hidup dan bergaul secara sosial turut serta mempengaruhi pola keberagamaan seorang siswa. ${ }^{19}$

Berdasarkan hasil penelitian yang telah dilakukan diketahui bahwa nilai thitung untuk variabel pembelajaran akidah akhlak $\left(X_{2}\right)$ sebesar 4,353 dengan nilai signifikan yang diperoleh sebesar 0,000 . Hal tersebut menunjukkan bahwa variabel pembelajaran akidah akhlak $\left(\mathrm{X}_{2}\right)$ memiliki nilai signifikansi < 0,05; maka hipotesis diterima. Dengan demikian dapat dikatakan bahwa pembelajaran akidah akhlak $\left(\mathrm{X}_{2}\right)$ berpengaruh positif dan signifikan secara parsial terhadap perilaku keberagaman siswa (Y).

Hal ini sejalan dengan penelitian yang dilakukan oleh Siska Fitri Yanti ${ }^{20}$ berjudul "Pengaruh Pembelajaran Aqidah Akhlak Terhadap Perilaku Siswa di Madrasah Aliyah Negeri Kampar Timur". Hasil penelitian menunjukkan adanya pengaruh yang signifikan antara pembelajaran aqidah akhlak terhadap perilaku siswa di Madrasah Aliyah Negeri Kampar Timur. Kondisi ini juga sesuai dengan hasil observasi yang telah dilakukan di lapangan bahwa pembelajaran akidah akhlak berdampak positif terhadap perilaku siswa di sekolah. Sebab pada pembelajaran Aqidah Akhlak diajarkan tentang berperilaku baik yang sesuai dengan ajaran agama islam seperti: diajarkan norma, moral, etika dan cara tata krama yang baik, cara bergaul, cara menghargai orang dan sebagainya. ${ }^{21}$

\section{Pengaruh Bimbingan Konseling $\left(X_{1}\right)$ dan Pembelajaran Akidah Akhlak $\left(X_{2}\right)$ terhadap Perilaku Keberagamaan Siswa (Y)}

Berdasarkan uji F ditemukan bahwa nilai F sebesar 17,540 dengan nilai signifikan yang diperoleh sebesar 0,000 di mana nilai tersebut lebih kecil dari 0,05. Dengan demikain dapat dijelaskan bahwa terdapat pengaruh positif dan signifikan secara bersama-sama antara variabel bimbingan konseling $\left(X_{1}\right)$ dan pembelajaran akidah

${ }^{18}$ Sufiani, Efektivitas Pembelajaran Aqidah Akhlak Berbasis Manajemen Kelas, Jurnal Al-

Ta'dibVol. 10 No. 2, Juli-Desember, 2017

${ }^{19}$ Kadir. 2008. Pola Perilaku Keberagamaan Siswa SMA Negeri Kabupaten Mais Ok War I. Jurnal "Al-Qalam" No. Xxii Tahun Xiv Edisi Juli - Desember 2008

${ }^{20}$ Siska Fitri Yanti. Pengaruh Pembelajaran Aqidah Akhlak Terhadap Perilaku Siswa di Madrasah Aliyah Negeri Kampar Timur. JOM FISIP Vol. 4 No. 1 - Februari 2017

${ }^{21}$ Siska Fitri Yanti. Pengaruh Pembelajaran Aqidah Akhlak Terhadap Perilaku Siswa di Madrasah Aliyah Negeri Kampar Timur. JOM FISIP Vol. 4 No. 1 - Februari 2017 
akhlak $\left(\mathrm{X}_{2}\right)$ terhadap variabel perilaku keberagamaan siswa $(\mathrm{Y})$, sehingga hipotesis diterima. Hal ini dapat diartikan bahwa apabila bimbingan konseling $\left(\mathrm{X}_{1}\right)$ dan pembelajaran akidah akhlak $\left(\mathrm{X}_{2}\right)$ memiliki peningkatan nilai maka perilaku keberagamaan siswa (Y) juga akan meningkat.

Hal ini sejalan dengan penelitian Resky Pratiwi yang menunjukkan hasil bahwa terdapat pengaruh yang signifikan antara pembelajaran Aqidah akhlak terhadap perilaku peserta didik kelas V di MIN 2 Makassar. Hal ini tercermin dalam output SPSS Berdasarkan tabel Anova dapat kita ketahui bawa sig.deviation from linierity sebesar 0,235 dalam hal ini nilai 0,235>0,05 yang merupakan standar signifikansi maka dapat kita simpulkan bahwa diterima yang artinya terdapat hubungan linier antara variabel pembelajaran aqidah dengan perilaku peserta didik. ${ }^{22}$ Onyango, Aloka, Raburu dalam penelitiannya yang berjudul "Effectiveness of Guidance and Counseling in the Management of Student Behaviour in Public Secondary Schools in Kenya" menunjukkan bahwa secara statistik signifikan ada hubungan antara bimbingan dan konseling dan manajemen perilaku siswa. Korelasi Pearson Koefisien $r=0,503$ tercapai, yang menunjukkan itu bimbingan dan konseling cukup efektif dalam manajemen perilaku siswa. ${ }^{23}$

Perilaku secara pengertian adalah tingkah laku manusia dan berbentuk dari jiwa, dan yang tertera di kamus besar Indonesia bahwa perilaku adalah tanggapan atau reaksi individu terhadap rangsangan atau lingkungan. ${ }^{24}$ Siswa di sekolah memiliki perilaku yang beragam, hal ini dipengaruhi oleh beberapa faktor baik dari faktor internal maupun dari faktor eksternal. Untuk itu pembelajaran akidah akhlak dan bimbingan konseling penting diterapkan di sekolah supaya dapat membantu siswa dalam berperilaku baik. Tujuan bimbingan konseling yang paling utama adalah untuk membantu siswa dalam mengembangkan kemampuan-kemampuan yang dimilikinya dan mendorong para guru untuk menyediakan atmosfer pembelajaran di kelas yang lebih kondusif. Dalam pembelajaran akidah akhlak terdapat suatu aktivitas pembentukan perubahan prilaku melalui bimbingan terhadap peserta didik supaya dapat memahami dan mengamalkan ajaran agama Islam. ${ }^{25}$

\section{KESIMPULAN}

Berdasarkan rumusan masalah beserta analisis data dan pembahasan yang dikemukakan pada bab sebelumnya, maka dapat dikemukakan beberapa kesimpulan penelitian sebagai berikut:

\footnotetext{
${ }^{22}$ Resky Pratiwi. 2018. Pengaruh Pembelajaran Aqidah Akhlak Terhadap Perilaku Peserta Didik Kelas V di MIN 2 Makassar. Skripsi UIN Alauddin Makassar

${ }^{23}$ Oyango, Pamela Awour, dkk. 2018. Effectiveness of Guidance and Counseling in the Management of Student Behaviour in Public Secondary Schools in Kenya. International Journal of Applied Psychology 2018, 8(1): 6-11

${ }^{24}$ Anonimous, Pedoman Pendidikan Agama Islam, (Jakarta: Depag RI 1996). hlm. 755

${ }^{25}$ Rohmatun Aulia. 2018. Pengaruh Pembelajaran Aqidah Akhlak Terhadap Karakter Peserta Didik Kelas VIII DI MTS Darul A'mal Kota Metro Tahun Pelajaran 2017/2018
} 
1. Bimbingan konseling berpengaruh positif dan signifikan terhadap perilaku keberagamaan siswa, yang mana dapat diartikan bahwa bimbingan konseling berperan dalam meningkatkan perilaku keberagamaan siswa.

2. Pembelajaran akidah akhlak berpengaruh positif dan signifikan terhadap perilaku keberagamaan siswa, yang mana dapat diartikan bahwa Pembelajaran akidah akhlak berperan dalam meningkatkan perilaku keberagamaan siswa.

3. Bimbingan konseling dan pembelajaran akidah akhlak secara bersama-sama berpengaruh positif dan signifikan terhadap perilaku keberagamaan siswa

\section{REFERENSI}

Anonimous. (1996). Pedoman Pendidikan Agama Islam. Jakarta: Depag RI

Diniyah, Lutfi. (2016). Pengaruh Bimbingan Konseling Terhadap Perubahan Tingkah Laku Siswa Kelas IX DI SMP NEGERI 2 Kandat Kabupaten Kediri Tahun Pelajaran 2014/2015. Skripsi Universitas Nusantara PGRI Kediri. 2016

Kadir. (2008). Pola Perilaku Keberagamaan Siswa SMA Negeri Kabupaten Mais Ok War I. Jurnal "Al-Qalam" No. Xxii Tahun Xiv Edisi Juli - Desember 2008

Oyango, Pamela Awour, dkk. (2018). Effectiveness of Guidance and Counseling in the Management of Student Behaviour in Public Secondary Schools in Kenya. International Journal of Applied Psychology 2018, 8(1): 6-11

Pratiwi, Resky. (2018). Pengaruh Pembelajaran Aqidah Akhlak Terhadap Perilaku Peserta Didik Kelas V di MIN Makassar. Skripsi UIN Alauddin Makassar

Sufiani. 2017. Efektivitas Pembelajaran Aqidah Akhlak Berbasis Manajemen Kelas, Jurnal Al-Ta'dibVol. 10 No. 2, Juli-Desember

Suharsimi, Arikunto. 2005. Manajemen Penelitian. Jakarta : Rineka Cipta

Susanto, Ahmad. (2018). Bimbingan dan Konseling di Sekolah (Konsep Teori dan Aplikasinya). Jakarta, Prenadamedia Group, hal.2

Takapaha, David Yohanis, dkk. (2016). Pengaruh Komunikasi Antar Persona Guru Bimbingan Konseling Terhadap Perilaku Siswa (Studi Pada Siswa SMK Negeri 2 Kendari)

Widyasari, Devie. (2012). Pengaruh Bimbingan Konseling Dan Kedisiplinan Belajar Siswa Terhadap Prestasi Belajar Siswa Kelas XI Pada SMA Negeri I Jatisrono Wonogiri Tahun Ajaran 2011/2012

Yanti, Siska Fitri. (2017). Pengaruh Pembelajaran Aqidah Akhlak Terhadap Perilaku Siswa di Madrasah Aliyah Negeri Kampar Timur. JOM FISIP Vol. 4 No. 1 Februari 2017 